\title{
Antifungal effect of cumin essential oil alone and in combination with antifungal drugs
}

\author{
SAHADEO PATIL ${ }^{1, \bullet}$, PANKAJ MAKNIKAR ${ }^{1}$, SUSHILKUMAR WANKHADE ${ }^{1}$, CHANDRAKIRAN UKESH ${ }^{1}$, \\ MAHENDRA RAI ${ }^{2}$
}

\author{
${ }^{1}$ Department of Microbiology, Shri Shivaji Science College, Amravati 444603, Maharastra, India. Tel. +91-9372433429; \\ "email: sdpatil20957@yahoo.co.in \\ ${ }^{2}$ Department of Biotechnology, Sant Gadge Baba Amravati University, Amravati-444602, Maharashtra, India
}

Manuscript received: 6 March 2015. Revision accepted: 30 April 2015.

\begin{abstract}
Patil S, Maknikar P, Wankhade S, Ukesh C, Rai M. 2015. Antifungal effect of cumin essential oil alone and in combination with antifungal drugs. Nusantara Bioscience 7: 55-59. We report evaluation of antifungal activity of cumin seed oil and its pharmacological interactions when used in combination with some of the widely used conventional antifungal drugs using CLSI broth microdilution, agar disc diffusion and checkerboard microtitre assay against Candida. The essential oil was obtained from cumin seeds using hydrodistillation technique and was later evaluated for the presence of major chemical constituents present in it using gas chromatography and mass spectrometry (GC-MS) assay. The GC-MS assay revealed the abundance of $\gamma$-terpinene (35.42\%) followed by $p$-cymene $(30.72 \%)$. The agar disc diffusion assay demonstrated highly potent antifungal effect against Candida species. Moreover, the combination of cumin essential oil (CEO) with conventional antifungal drugs was found to reduce the individual MIC of antifungal drug suggesting the occurrence of synergistic interactions. Therefore, the therapy involving combinations of CEO and conventional antifungal drugs can be used for reducing the toxicity induced by antifungal drugs and at the same time enhancing their antifungal efficacy in controlling the infections caused due to Candida species.
\end{abstract}

Keywords: Cuminum cyminum, essential oil composition, antifungal activity, combinational study

\section{INTRODUCTION}

The sudden rise in the emergence of opportunistic fungal infections is of paramount concern as a cause of morbidity and mortality, which can be the manifestations of any of these immunosuppressive treatments involving use of chemotherapy, immunosuppressants, organ transplantation, HIV infections, consumption of heavy dose of antibiotics and other prolonged immunotherapy (Pappas 2010). The challenges to these infections are further severed by the tolerance shown by these pathogens to the available antimicrobial drugs over a period of time sooner or later. Candida species are yeast-like fungi, which are the normal inhabitants of skin and gastrointestinal microflora of human beings and can thrive without imposing any danger under normal conditions. However, under weak immunological barriers, they can manifest into serious health ailments (Bicanic and Harrison 2014).

Brown and Netea (2012) reported that the patients from the Western societies which are severely ill are only prone to the fungal infections including both immunocompromised and healthy patients whereas patients from developing countries are susceptible to the infections caused by wide range of fungi regardless of their health status. Despite the developments in the antifungal therapy, the mortality due to fungal infection can be traced up to 30$50 \%$. Amphotericin B is generally considered primary line of defense to tackle infections by Candida species and is often given in combination with more efficacious and less toxic systemic azole antifungal drugs such as fluconazole, miconazole, ketoconazole, etc. However, amphotericin B overdose can be nephro and hepatotoxic (Safdar et al. 2010) and indiscriminate use of azole drug such as fluconazole can result in its intrinsic tolerance among $C$. albicans and non-albicans Candida species (Sanglard et al. 2003). Therefore, resistance to the azole antifungal drugs against Candida species has become predictable over a period of time which can be attributed to its fungistatic rather than the fungicidal nature in general (Vandenbosch et al. 2010). Moreover, these problems are further severed by the emergence of cross-resistance to other antifungal drugs of same or different class too (Panackal et al. 2006; Chen et al. 2012). Hence, novel strategies are imperative in controlling the infections caused by Candida species. On the backdrop of this, combinational therapy using conventional antifungal drugs and the plant-based products has come up with promising outcomes.

Essential oils are some of the vital secondary metabolites which have been assessed extensively for their antibacterial, antifungal, antitumor and antioxidative efficacies (Begnami et al. 2010; Khan et al. 2010; Prakash et al. 2010, 2012; Al-Ja'fari et al. 2011; Lv et al. 2011; Nikolić et al. 2014). In addition, essential oils or their individual chemical constituents when combined with conventional antibacterial and antifungal drugs have been identified with their capability in enhancing the potency of 
these drugs (Mahboubia and Bidgoli 2010; Amber et al. 2010; Silva et al. 2011; Ahmad et al. 2013). Cuminum cyminum (cumin) is an annual herb belonging to the Apiaceae family widely cultivated in India, China, and several Middle East Asian countries (Thippeswamy and Naidu 2005; Oroojalian et al. 2010). Cumin seeds possess a characteristic aroma due to its essential oil content, owing to which is widely used in the different cuisines across the globe and ranks only second in the world's most popular spices (Hajlaoui et al. 2010). Cumin essential oil (CEO) has been identified with potent antibacterial, antifungal, insecticidal and antioxidative efficacies (Iacobellis et al. 2005; Gachkar et al. 2007; Packiavathy et al. 2012).

In the current study, antifungal activity of CEO was evaluated alone as well as in combination with four antifungal drugs including fluconazole, miconazole and amphotericin B using disc diffusion, CLSI broth microdilution method and checkerboard assay (Saad et al. 2010).

\section{MATERIALS AND METHODS}

\section{Essential oil extraction and chemical composition}

The cumin seeds (Cuminum cyminum) were purchased from local market and were finely ground before hydrodistillation using Clevenger apparatus for $3 \mathrm{~h}$. The extract was dried over anhydrous sodium sulfate and after filtration was refrigerated in sealed glass vials at $4^{\circ} \mathrm{C}$ until further use (Palmeira-de-Oliveira et al. 2012). The chemical constituents of essential oil were analyzed by using GC-MS assay in which retention times of chromatographic peaks were identified by comparing with WILEY8.LIB and NIST05s.LIB databases.

\section{Test organisms}

Five clinical isolates belonging to Candida species including $C$. albicans $(n=3), C$. glabrata $(n=1)$ and $C$. krusei $(n=1)$ were obtained from PDMMC Hospital, Amravati, Maharastra, India.

\section{Disc diffusion assay}

The CEO was assessed for its antifungal efficacy using CLSI disc diffusion assay (CLSI 2009). Sterile paper discs (6 $\mathrm{mm}$ diameter) procured from HiMedia, India was impregnated with an aliquot of $20 \mu \mathrm{L}$ of 10,20 and $30 \%$ CEO in DMSO (v/v) and placed on to sterile Sabouraud dextrose agar (SDA) plates prelawned with yeast cultures in $\log$ phase. The plates were left undisturbed for $30 \mathrm{~min}$ at room temperature in order to diffuse the essential oil and incubated at $37^{\circ} \mathrm{C}$ for $48 \mathrm{~h}$. The diameters of zone of inhibition were recorded in millimeter. The experiment was performed in triplicate and mean values were recorded.

\section{Determination of MIC and FIC index}

The minimum inhibitory concentration (MIC) of four antifungal drugs (fluconazole, miconazole and amphotericin B), as well as CEO, was determined using broth microdilution method according to the guidelines CLSI guidelines (CLSI 2008). The plates were incubated at $37^{\circ} \mathrm{C}$ for $48 \mathrm{~h}$ and MIC endpoints were recorded as the highest dilution resulting in complete inhibition of any visible growth in case of amphotericin $\mathrm{B}$ and CEO whereas, in case of fluconazole, miconazole and $80 \%$ growth reduction was counted as MIC endpoint (Alexander et al. 2007; Shin and Lim 2004). The fractional inhibitory concentration index (FICI) was defined as summation of fractional inhibitory concentration (FIC) of antifungal drug and FIC of essential oil and was evaluated by using checkerboard assay. The interactions observed were interpreted as synergistic, additive and antagonistic with FICI values of $\leq 0.5,>0.5$ and $\leq 2$ and $>2$ respectively (Saad et al. 2010).

\section{RESULTS AND DISCUSSION}

The results of qualitative and quantitative analysis of CEO using GC-MS assay is as shown in Table 1. The hydrodistillation of cumin seed oil gave a yield of 3.9 to $4.5 \%$ (v/w). GC-MS analysis of the CEO was done with the identification of ten major chemical constituents as shown in Table 1. The CEO deciphered highest content of $\gamma$-terpinene and $p$-cymene with 35.42 and $30.72 \%$ concentrations respectively. In addition to this, the next eight components were cuminal (5.79\%), $\beta$-pinene $(5.58 \%)$, $\alpha$-pinene $(4.65 \%)$, carbicol $(4.25 \%), 2$-caren-10al $(3.84 \%)$, limonene $(3.36 \%), 1,8$-cineole $(3.35 \%)$ and $\alpha$ terpinene $(3.12 \%)$. The reports of present study showed $\alpha$ terpinene $(35.42 \%)$ and $p$-cymene $(30.72 \%)$ as major compounds in CEO. According to the report of Gachkar et al. (2007), essential oil of C. cyminum grown in Iran contain $\alpha$-pinene $(29.1 \%), 1,8$-cineole $(17.9 \%)$ and linalool $(10.4 \%)$ as the major compounds. In another study, Tunisian variety of Cuminum cyminum contained

Table 1. Chemical constituents of CEO

\begin{tabular}{llll}
\hline Peak no. & RT $(\mathbf{m i n})$. & Compound name & Peak area $(\%)$ \\
\hline 1 & 9.63 & $\alpha$-Pinene & 4.65 \\
2 & 9.74 & 1,8-Cineole & 3.25 \\
3 & 10.12 & Limonene & 3.36 \\
4 & 10.33 & $\alpha$-Terpinene & 3.12 \\
5 & 10.58 & $\beta$-Pinene & 5.58 \\
6 & 10.97 & Cuminaldehyde & 5.79 \\
7 & 11.46 & $\gamma$-Terpinene & 35.42 \\
8 & 12.18 & $p$-Cymene & 30.72 \\
9 & 12.57 & Carbicol & 4.25 \\
10 & 13.05 & 2-Caren-10-al & 3.84 \\
\hline
\end{tabular}

Table 2. Antifungal activity of CEO against Candida species

\begin{tabular}{lccc}
\hline \multirow{2}{*}{ Test organism } & \multicolumn{3}{c}{$\begin{array}{c}\text { Zone of inhibition }(\mathbf{m m}) \text { at CEO (\%) in } \\
\text { DMSO }(\mathbf{v} / \mathbf{v}) \boldsymbol{\mu L}(\mathbf{M e a n} \pm \text { SD) }\end{array}$} \\
\cline { 2 - 4 } & $\mathbf{1 0 \%}$ & $\mathbf{2 0 \%}$ & $\mathbf{3 0 \%}$ \\
\hline C. albicans $(\mathrm{C} 16)$ & $42.67 \pm 2.08$ & $44.00 \pm 2.22$ & $49.67 \pm 0.58$ \\
C. albicans $(\mathrm{C} 27)$ & $31.33 \pm 1.52$ & $34.33 \pm 2.08$ & $42.33 \pm 2.08$ \\
C. albicans $(\mathrm{C} 29)$ & $37.00 \pm 1.73$ & $43.67 \pm 1.52$ & $44.33 \pm 2.08$ \\
C. glabrata $(\mathrm{C} 39)$ & $36.67 \pm 2.08$ & $42.67 \pm 1.52$ & $46.67 \pm 0.57$ \\
C. krusei $(\mathrm{C} 45)$ & $31.00 \pm 1.00$ & $33.00 \pm 1.73$ & $40.67 \pm 1.53$ \\
\hline
\end{tabular}


Table 3. Combinational effects of cumin with antifungal drugs against Candida species

\begin{tabular}{|c|c|c|c|c|c|c|}
\hline Isolate & Combination & MICa & MICc & FIC & FICI & Type of interaction \\
\hline \multirow{4}{*}{ C16 } & C. albicans & & & & & \\
\hline & Cumin EO-fluconazole & & & & & \\
\hline & Cumin EO & 0.08 & 0.005 & 0.06 & 0.31 & Synergistic \\
\hline & Fluconazole & 256 & 64 & 0.25 & & \\
\hline \multirow[t]{3}{*}{$\mathrm{C} 27$} & Cumin EO-fluconazole & & & & & \\
\hline & Cumin EO & 0.16 & 0.02 & 0.125 & 0.19 & Synergistic \\
\hline & Fluconazole & 256 & 16 & 0.06 & & \\
\hline \multirow[t]{3}{*}{$\mathrm{C} 27$} & Cumin EO-amphotericin B & & & & & \\
\hline & Cumin EO & 0.16 & 0.02 & 0.125 & 0.19 & Synergistic \\
\hline & Amphotericin B & 2 & 0.125 & 0.06 & & \\
\hline \multirow[t]{4}{*}{$\mathrm{C} 29$} & Cumin EO-miconazole & & & & & \\
\hline & Cumin EO & 0.31 & 0.08 & 0.25 & 0.5 & Synergistic \\
\hline & Miconazole & 8 & 2 & 0.25 & & \\
\hline & C. glabrata & & & & & \\
\hline \multirow[t]{4}{*}{ C39 } & Cumin EO-fluconazole & & & & & \\
\hline & Cumin EO & 0.08 & 0.02 & 0.25 & 0.375 & Synergistic \\
\hline & Fluconazole & 128 & 16 & 0.125 & & \\
\hline & C. krusei & & & & & \\
\hline \multirow[t]{3}{*}{$\mathrm{C} 45$} & Cumin EO-fluconazole & & & & & \\
\hline & Cumin EO & 0.08 & 0.02 & 0.25 & 0.375 & Synergistic \\
\hline & Fluconazole & 128 & 16 & 0.125 & & \\
\hline
\end{tabular}

Note: MICa: MIC of EO/antifungal drug alone; MICc: MIC of EO/antifungal drug in combination; FIC: Fractional inhibitory concentration; FICI: Fractional inhibitory concentration index (FIC of EO + FIC of antifungal drug).

cuminaldehyde $(39.48 \%)$, gamma-terpinene $(15.21 \%)$, Ocymene $(11.82 \%)$, and beta-pinene $(11.13 \%)$ as major components (Hajlaoui et al. 2010).

Table 2 illustrates the results obtained for antifungal activity of CEO using agar disc diffusion assay. The result of CEO antifungal activity was studied at different CEO concentration of 10,20 and $30 \%$. All the concentrations of CEO were found to be significant antifungal agent against all the tested candidal isolates with the zone of inhibition in between $31.00 \pm 1.00$ to $49.67 \pm 0.58 \mathrm{~mm}$. The zones of inhibition were found to be increasing with the increase in the concentration of CEO which reflected its dosedependent inhibitory potential. The results of MIC of CEO when tested alone against Candida species obtained by broth microdilution technique demonstrated the values in between 0.08 and $0.31 \mu \mathrm{g} / \mathrm{mL}$. The strong antifungal efficacy of CEO was also evident with its lower MIC values (Table 3). The antimicrobial potential of essential oils is governed by the occurrence of its major and minor chemical constituents. Several investigators have coupled strong inhibitory action of CEO to its phenolic and monoterpenic contents (Naeini et al. 2013). The terpenes in CEO are known to affect respiration in Candida probably due to its damaging effects on mitochondria. This reaction renders the morphological alterations in the Candida cell leading to cell death (Tepe et al. 2004). Cuminum cyminum was of $\gamma$-terpinene chemotype and thus, this chemical constituent might have played a key role in killing the candidal population. MIC values $(128-256 \mu \mathrm{g} / \mathrm{mL})$ of selected antifungal drugs against the test organisms demonstrated their strong intrinsic resistance to them when assessed alone (Table 3).

The results of checkerboard microtitre assay show the FICIs values ranging from 0.19 to 0.375 . The strategy involving combination of plant essential oils with conventional antifungal drugs has given encouraging results in the recent past (Rosato et al. 2009; Saad et al. 2010; Stringaro et al. 2014). Hence, the antifungal potential of CEO was further analyzed using checkerboard assay for the possible synergistic interactions. The treatment of CEO in combination with antifungal drugs showed significant decrease in the individual MICs of all the antifungal drugs. The combinations involving CEO with fluconazole and amphotericin B demonstrated lowest FICIs (0.19 each) expressing the occurrence of strong synergistic interactions (Saad et al. 2010). Combining the CEO with fluconazole and amphotericin B lowered the individual MICs of both the drugs by sixteen fold against $C$. albicans (C27). CEOmiconazole combination too expressed synergistic interaction by showing the FICI of 0.5. C. glabrata and $C$. krusei were both analyzed for possible synergistic interactions combining the CEO with fluconazole which showed identical FICIs of 0.375 each demonstrating the occurrence of synergistic interactions.

The mechanism of action of these combinations was not assessed in the current study. However, the possible synergistic action in enhancing the potency of combinations could be attributed to the individual as well as combined actions of both CEO chemical constituents and antifungal drugs. Azole drugs are known to act by 
inhibiting the lanosterol $14 \alpha$-demethylase, an important enzyme needed for ergosterol synthesis while polyenes antifungals, viz. amphotericin $\mathrm{B}$ acts by binding to the fungal membrane sterol rendering the membrane porous that manifests into leakage of cytoplasmic materials and ultimately the cell death (Balkis et al. 2002). The essential oils have been discussed earlier to have involved in the disruption of fungal cell membrane. It has also been reported earlier that, fluconazole is more hydrophilic compound unlike the other antifungal drug (e. g. ketoconazole which is lipophilic) therefore, is poorly absorbed by the cell membrane of Candida that is lipophilic in nature (Consiglieri et al. 2010). Thus, the porosity inducing trait of essential oil might have facilitated the entry of fluconazole through cell membrane when treated in combination thereby severing the cell membrane damage. Similarly, the same phenomenon might have assisted in the synergistic interactions produced in presence of other antifungal drugs such as miconazole and amphotericin B. Besides that, the strong antimicrobial potential of essential oils could be correlated to the abundance of different chemical constituents comprised by them. The individual chemical constituents of essential oil have been extensively examined for their biological activities but that can be the reflections of only certain fractions of essential oil rather than expressing the efficacy of essential oil as a whole. The highly abundant chemical constituents may act ferociously against pathogens but chances of other less prevalent chemical components possibly maneuvering their actions also could not be neglected (Bakkali et al. 2008). Therefore, the same principle could also be applied to the efficacy of combinations involving conventional antifungal drugs and CEO when prevalent as well as other scarcely present chemical constituents of essential oil could have facilitated the entry of antifungal drugs thereby increasing its efficacy against the Candida species.

From the outcomes of the current study, it was evident that CEO besides being potent antifungal agent when combined with conventional antifungal drugs such as fluconazole, miconazole and amphotericin B is more likely to reduce the individual MICs of these antifungal drugs moreover increasing their efficacy against Candida species. However, further research is imperative to assess its practical in vivo therapeutic applications.

\section{REFERENCES}

Ahmad A, Khan A, Manzoor N. 2013. Reversal of efflux-mediated antifungal resistance underlies synergistic activity of two monoterpenes with fluconazole. Eur J Pharm Sci 48: 80-86.

Alexander BD, Byrne TC, Smith KL, Hanson KE, Anstrom KJ, Perfect JR, Reller LB. 2007. Comparative evaluation of Etest and Sensititre Yeast one panels against the Clinical and Laboratory Standards Institute M27-A2 reference broth microdilution method for testing Candida susceptibility to seven antifungal agents. J Clin Microbiol 45: 698-706.

Al-Ja'fari A, Vila R, Freixa B, Tomi F, Casanova J, Costa J, Cañigueral S. 2011. Composition and antifungal activity of the essential oil from the rhizome and roots of Ferula hermonis. Phytomedicine 72: 1406-1413.
Amber K, Aijaz A, Immaculata X, Luqman KA, Nikhat M. 2010. Anticandidal effect of Ocimum sanctum essential oil and its synergy with fluconazole and ketoconazole. Phytomedicine 17: 921-925.

Bakkali F, Averbeck S, Averbeck D, Idaomar M. 2008. Biological effects of essential oils - A review. Food Chem Toxicol 46: 446-475.

Balkis MM, Leidich SD, Mukherjee PK, Ghannoum MA. 2002. Mechanisms of fungal resistance-An overview. Drugs 62: 1025-1040.

Begnami A, Duarte M, Furletti V, Rehder V. 2010. Antimicrobial potential of Coriandrum sativum L. against different Candida species in vitro. Food Chem 118: 74-77.

Bicanic TA, Harrison TS. 2014. Systemic fungal infections. Medicine 42 (1): 26-30.

Brown GD, Netea MG. 2012. Exciting developments in the immunology of fungal infections. Cell Host Microbe 11: 422-424.

Chen TC, Chen YH, Chen YC, Lu PL. 2012. Fluconazole exposure rather than clonal spreading is correlated with the emergence of Candida glabrata with cross-resistance to triazole antifungal agents. Kaohsiung J Med Sci 28 (6): 306-315.

CLSI [Clinical Laboratory Standards Institute] 2008. Reference method for broth dilution antifungal susceptibility testing of yeast; approved standard-third edition. CLSI document: M27-A3. CLSI, Wayne, PA.

CLSI [Clinical Laboratory Standards Institute] 2009. Method for antifungal disk diffusion susceptibility testing in yeasts; approved guideline-second edition. CLSI document: M44-A2. CLSI, Wayne, PA.

Consiglieri VO, Mourão S, Sampaio M, Granizo P, Garcia P, Martinello V, Spricigo R, Ferraz HG. 2010. Improvement of fluconazole flowability and its effect on dissolution from tablets and capsules. Braz J Pharm Sci 46: 115-120.

Gachkar L, Yadegari D, Rezaei MB, Taghizadeh M, Shakiba AA, Rasooli I. 2007. Chemical and biological characteristics of Cuminum cyminum and Rosmarinus officinalis essential oils. Food Chem 102: 898-904.

Hajlaoui H, Mighri H, Noumi E, Snoussi M, Trabelsi N, Ksouri R, Bakhrouf A. 2010. Chemical composition and biological activities of Tunisian Cuminum cyminum L. essential oil: A high effectiveness against Vibrio spp. strains. Food Chem Toxicol 48: 2186-2192.

Iacobellis NS, Lo Cantore P, Capasso F, Senatore F. 2005. Antibacterial activity of Cuminum cyminum L. and Carum carvi L. essential oils. J Agric Food Chem 53: 57-61.

Khan A, Ahmad A, Akhtar F, Yousuf S, Xess I, Khan L, Manzoor N. 2010. Ocimum sanctum essential oil and its active principles exert their antifungal activity by disrupting ergosterol biosynthesis and membrane integrity. Res Microbiol 161: 816-823.

Lv F, Liang H, Yuan Q, Li C. 2011. In vitro antimicrobial effects and mechanism of action of selected plant essential oil combinations against four food-related microorganisms. Food Res Int 44: 30573064

Mahboubia M, Bidgoli F. 2010. Antistaphylococcal activity of Zataria multiflora essential oil and its synergy with vancomycin. Phytomedicine 17: 548-550.

Naeini A, Naderi NJ, Shokri H. 2013. Analysis and in vitro anti-Candida antifungal activity of Cuminum cyminum and Salvadora persica herbs extracts against pathogenic Candida strains. J Medical Mycol 24: 1318.

Nikolić M, Glamočlija J, Ferreira I, Calhelha R, Fernandes Â, Marković T, Marković D, Giwelie A, Soković M. 2014. Chemical composition, antimicrobial, antioxidant and antitumor activity of Thymus serpyllum L., Thymus algeriensis Boiss. and Reut and Thymus vulgaris L. essential oils. Ind Crops Products 52: 183-190.

Oroojalian F, Kasra-Kermanshahi R, Azizi M, Bassami MR. 2010. Phytochemical composition of the essential oils from three Apiaceae species and their antibacterial effects on food-borne pathogens. Food Chem 120: 765-770.

Packiavathy I, Agilandeswari P, Musthafa K, Pandian S, Ravi A. 2012. Antibiofilm and quorum sensing inhibitory potential of Cuminum cyminum and its secondary metabolite methyl eugenol against Gramnegative bacterial pathogens. Food Res Int 45: 85-92.

Palmeira-de-Oliveira A, Gaspara C, Palmeira-de-Oliveira R, Silva-Dias A, Salgueiro L, Cavaleiro C, Pina-Vaz C, Martinez-de-Oliveiraa J, Queiroza JA, Rodrigues AG. 2012. The anti-Candida activity of Thymbra capitata essential oil: Effect upon pre-formed biofilm. J Ethnopharmacol 140: 379-383.

Panackal AA, Gribskov JL, Staab JF, Kirby KA, Rinaldi M, Marr KA. 2006. Clinical significance of azole antifungal drug cross-resistance in Candida glabrata. J Clin Microbiol 44 (5): 1740-1743. 
Pappas PG. 2010. Opportunistic fungi: a view of the future. Am J Med Sci 340: 253-257.

Prakash B, Shukla R, Singh P, Kumar A, Mishra P, Dubey N. 2010. Efficacy of chemically characterized Piper betle L. essential oil against fungal and aflatoxin contamination of some edible commodities and its antioxidant activity. Int J Food Microbiol 142: 114-119.

Prakash B, Singh P, Mishra P, Dubey N. 2012. Safety assessment of Zanthoxylum alatum Roxb. essential oil, its antifungal, antiaflatoxin, antioxidant activity and efficacy as antimicrobial in preservation of Piper nigrum L. fruits. Int J Food Microbiol 153: 183-191.

Rosato A, Vitali C, Piarulli M, Mazzotta M, Argentieri M, Mallamaci R. 2009. In vitro synergic efficacy of the combination of nystatin with the essential oils of Origanum vulgare and Pelargonium graveolens against some Candida species. Phytomedicine 16: 972-975.

Saad A, Fadli M, Bouaziz M, Benharref A, Mezrioui NE, Hassani L. 2010. Anticandidal activity of the essential oils of Thymus maroccanus and Thymus broussonetii and their synergism with amphotericin B and fluconazol. Phytomedicine 17: 1057-1060.

Safdar A, Ma J, Saliba F, Dupont B, Wingard JR, Hachem RY, Mattiuzzi GN, Chandrasekar PH, Kontoyiannis DP, Rolston KV, Walsh TJ, Champlin RE, Raad II. 2010. Drug-induced nephrotoxicity caused by amphotericin B lipid complex and liposomal amphotericin B: a review and meta-analysis. Medicine (Baltimore) 89 (4): 236-244.

Sanglard D, Ischer F, Parkinson T, Falconer D, Bille J. 2003. Candida albicans mutations in the ergosterol biosynthetic pathway and resistance to several antifungal agents. Antimicrob Agents Chemother 47: 2404-2412.

Shin S, Lim S. 2004. Antifungal effects of herbal essential oils alone and in combination with ketoconazole against Trichophyton spp. J Appl Microbiol 97: 1289-1296.

Silva F, Ferreira S, Duartea A, Mendonc DI, Domingues FC. 2011. Antifungal activity of Coriandrum sativum essential oil, its mode of action against Candida species and potential synergism with amphotericin B. Phytomedicine 19: 42-47.

Stringaro A, Vavala E, Colone M, Pepi F, Mignogna G, Garzoli S, Cecchetti S, Ragno R, Angiolella L. 2014. Effects of Mentha suaveolens essential oil alone or in combination with other drugs in Candida albicans. Evid Based Compl Alternat Med 2014: 125904. doi: $10.1155 / 2014 / 125904$.

Tepe B, Daferera D, Kmen MN, Polissiou M, Kmen AS. 2004. In vitro antimicrobial and antioxidant activities of the essential oils and various extracts of Thymus eigii M. Zohary et P.H. Davis. J Agric Food Chem 52: 1132-1137.

Thippeswamy NB, Naidu KA. 2005. Antioxidant potency of cumin varieties cumin, black cumin, and bitter cumin-on antioxidant systems. Eur Food Res Technol 220: 472-476.

Vandenbosch D, Braeckmans K, Nelis H, Coenye T. 2010. Fungicidal activity of miconazole against Candida spp. biofilms. J Antimicrob Chemother 65: 694-700. 